\title{
Difficulties of Verbal Interactions in French: Case of Student in the Department of L.E.A in the University of Dschang
}

Noukio Germaine Bienvenue

Chercheure En Sciences Sociales, Centre National de l'Education, MINRESI Yaoundé Cameroun

\author{
DOI: $10.36348 /$ sijll.2021.v04i02.005 \\ | Received: 07.02.2021 | Accepted: 18.02.2021 | Published: 24.02.2021
}

*Corresponding author: Noukio Germaine Bienvenue

\section{Abstract}

In this global village characterized by communication, globalization and verbal interaction; these different words have become obligatory that we cannot do nothing without them. Dschang University, provides efforts to students to enable them to communicate. One of its primary objectives is to provide the student with an effective tool allowing them to easily communicate with others in specific social circumstances. To learn and master a language is to be able to communicate in that language, therefore to act and interact effectively, by speaking it correctly. How can we assess the effectiveness of this communication in the university environment of Dschang?

Keywords: Communication, interaction, linguistic, learner, French language.

Copyright (C) 2021 The Author(s): This is an open-access article distributed under the terms of the Creative Commons Attribution 4.0 International License (CC BY-NC 4.0) which permits unrestricted use, distribution, and reproduction in any medium for non-commercial use provided the original author and source are credited.

\section{INTRODUCTION}

From the obvious reality observed during the interviews and exchanges between colleagues, comrades and friends it became evident that they speak without hearing each other, making verbal interactions the object of our investigation. This reality shows that there are real difficulties encountered by learners in the French courses in the University of Dschang when they interact. With regard to this situation, it seems important to us to highlight the causes which are at its origin. Such a problem leads us to carry out the present study. This theme falls within the field of language sciences because its study aims much more at delimiting the psychological, socio-cultural and cognitive factors that influence the good practice of successful communication. Taking into account all that has been said, it seems fair to ask: What are the various deficits that occur when practicing verbal communication and what are the causes?

The interest of verbal interaction, which focuses on improving and mastering the use of language, led us to this study. This study of the failure of old teaching methods neglecting any aspect of interaction. So, the main objective of this present research is to highlight the destructive difficulties which led to the crucial emergence of the lack of communication in this university environment and to propose solutions to these difficulties, without forgetting to sensitize the French language learners of the university on the importance of verbal interactions in their mastery of the language.

Faced with this problem, our reflection is directed towards certain linguistics difficulties linked to poor teaching / learning; certain psychological difficulties, due to their bad images or representation of the French language, certain social difficulties among others the origin of an ironic behavior towards the speaker.

\section{Concepts}

Communication is part of several fields of study and constitutes the common point on which they converge. Among these disciplines we can cite those belonging to the language sciences, in particular linguistics. Being omnipresent, its use covers several areas and therefore its meaning varies from area to area.

Larousse dictionary defines communication as:

1. "The act of communicating with someone, of being in contact with others, in general through language; verbal exchange between a speaker and an interlocutor from whom he requests a response; Language and the telephone are means of communication "; 
Noukio Germaine Bienvenue., Sch Int J Linguist Lit, Feb, 2021; 4(2): 59-64

2. "Action, the act of communicating, of transmitting something; Communication fromheat to a body";

3. "The action of putting things in relation, in connection, in contact; Establish communication between two pipes";

4. "Connection and conversation of two correspondents by telephone or by another means of telecommunication."

5. "Presentation given to a group and in particular to a learned society, in a congress, etc., information, written or oral, given to a group, an organization; Communication to the press."

In this study we will focus our attention on the first definition of the Larousse dictionary because it covers the human and social aspect of communication.

The appearance of the word "communicate" marked the 14th century with the meaning of "to share", "to relate" and "to make known". From these general meanings, the meaning of the word "communication" evolves over time to designate not only the act of communicating but also the relationships between human beings as evidenced by the research fields of language sciences.

J. Dubois's [1] Dictionary of Linguistics and Language Sciences also suggests the definition of "communication" in the following: "Communication is the verbal exchange between a speaking subject, which produces a statement intended for another speaking subject, and an interlocutor whose listening he requests and / or an explicit or implicit response (depending on the type of utterance). Communication is intersubjective."

This definition generally revolves around three main constitutive elements: the communication partners (communication actors or speaking subject who produces the statement), the communication situation (defined by the participants in the communication, the role they take during the communication, and the situational context) and the communication status (defined by the social or intersubjective distance between the speaking subject "I" and his interlocutors, and also by the way in which "I" contemplates its statement).

Dubois, through this definition, was only interested by verbal aspect of communication and did not take into consideration its non-verbal aspect, this aspect which is obviously indicated in S. Moirand [2]: "The exchange which is achieved through the use of verbal and non-verbal signs. "It is obvious that Dubois and Moirand share the same idea which consists in designating thecommunication by exchange, although communication is not limited to a simple exchange, the latter is part of the constituent units of verbal interaction, the latter in turn represents one of the two aspects of communication (verbal aspect, non-verbal aspect) and this means that communication is more general than exchange. So the relationship between communication and exchange is asymmetric defined by the relationship of inclusion. After defining communication according to some authors, we will take a look at some theories that speak of it in its social universe.

Like any notion, communication has marked the history of several disciplines and has been the pivot around which two major theories have been articulated. Chronologically These two theories follow one another, the first was mechanistic while the second is interactionist.

\section{Reviewing Literature on Communication}

It is within the field of linguistics that this conception fits with the work of R. Jacobson [3]. These works mark the sixties. Linguistics sees language as a communication tool and studies are more about code. This is the dominant position of linguistics in which, according to R. Vion [4]: "Communication, reduced to essentially denotative properties, reduced totransmission of information, focuses on the message.

From this perspective, we are dealing with a so-called message linguistics based on a communication model which promotes the enhancement of the processes of encoding and decoding of messages. However, it is the interest of general considerations like those of R. Jakobson [3] which offered to linguistics the point of departure and the opportunity to treat communication while inscribing with this treatment in a "mechanistic perception".

Nevertheless, this communication system has limits consisting to enhance a subject deprived of his interactional character and having neglected the psychological subject, the social subject or even the communication situation.

\section{Communication from an interactionist perspective}

As its name suggests, interactionist theory derives its principle from interpersonal interaction and is based on the relationship between the individual and his social environment, this principle finds its origin in the ethnography of communication.

\section{The ethnography of communication}

It was in 1962, from the conceptual divergence concerning the notion of language between Chomsky and Hymes, that the ethnography of communication emerged. Inspired by the ethnolinguistics of F. Boas 1911, E. Sapir 1931 and BL Whorf 1956 on the one hand and drawing on the linguistics of R. Jakobson [3] on the other hand, D. Hymes with the collaboration of other researchers, tried to create a new field of research taking as an object of study, unlike linguistics, the relations between communicative behaviors and their social contexts. The objective of this current research, 
Noukio Germaine Bienvenue., Sch Int J Linguist Lit, Feb, 2021; 4(2): 59-64

according to D. Hymes [5], is to develop a theory of communication as a cultural system inscribed in its social environment. Indeed, according to this author, the functioning of communication, similar to that of speech, is observed and treated within social life. For Hymes, founder of the ethnography of communication, communicative competence does not just boil down to being able to produceand interpret an infinite number of correct sentences as Chomsky [6] claims, but also to master the conditions of use of language, he sees in the use of language a process of communication which must be studied in its context of production, that means society. Moreover, G. de Salins [7], for his part, also noted:

"The ethnography of communication seeks above all to observe and describe recurrent behavioral structures in a determined situational framework, through the interactional study which is mainly based on the analysis of recursive patterns in social exchanges, that is study of what is usually done in a specific structure between actors social."

\section{Communicative competence}

For D. Hymes, knowing how to speak is mainly about mastering the conditions of appropriate use of the possibilities offered by the language. This author popularized his notion of "communication skill":

"When we consider individuals as capable of participating in social life as users of a language, we must, in reality, analyze their ability to integrate the use of language with other modes of communication such as gestures, facial expressions, grunts, etc. [...] In short, what we know and what we do with a language also depends on the place it occupies in the larger body of knowledge andcapacities entering into the various modes of communication."

These words suggest that the ability to perfect the use of language in social life implies mastery of sociological codes and variants, but also the ability to juggle the passage of a communicative code or a variant to others while respecting the conditions imposed by community varieties.

Both pragmatic and cultural knowledge is assumed as to the interpretative conventions that are in use in a given community. This skill, as KerbratOrecchioni [8-10] sees it, also corresponds to: "The set of skills allowing the speaking subject to communicate effectively in cultural situationsspecific."

Indeed, effective communication requires sufficient cultural knowledge and does not only call for a simple mastery of knowledge of grammar. Linguistic knowledge does not meet the requirements of communication that takes place ina social space full of dynamics and contacts that cover all interpersonal relationships governed by a cultural heritage. This heritage occupies a primordial place and plays an important role in the orientation of interpretations to ensure mutual understanding and even to analyze communicative acts as proven by Geertz C [11]: "Cultural and social norms represent a key to reading essential to interpret communicational processes."

Almost all of the authors cited in the above converge on a common point by focusing on the sociocultural ritual dimension but we see that the most explicit and detailed definition is that of J.P. Cuq [12] who emphasizes that communication competence is:

"The ability of a speaker to produce and interpret utterances in an appropriate manner, to adapt his speech to the communication situation by taking into account the external factors which condition him: the spatio-temporal framework, the identity of participants, their relationship and roles, the actions theyaccomplish, their adequacy to social standards, etc."

So communicative competence is the product of an assonant union between linguistic elements and extralinguistic elements. This study aims to assess the practice of the French language in the Faculty of Letters of the University of Dschang. We have chosen the concepts that best serve us to achieve the goal of detecting communication difficulties.

\section{Interaction as a general notion}

The notion of interaction is very vague and difficult to define because of its use in various fields. Linguists, didacticians and psychologists have tried to circumscribe this notion. Among them Robert Vion who declares that:" Interaction includes any conflicting and / or cooperative joint action involving two or more actors. As such, it covers conversational exchanges as well as financial transactions, love games and boxing matches. "According to this quote, Vion gave the interaction the social character of an executed fact, by any person and whatever the nature of that fact which is subject to rules in a situation involving the active presence of other individuals. He also evoked the notion of presence found in Goffman which clearly defined the interaction, as a mutual reciprocal action of two phenomena, of two people.

This definition gives two important elements, those of action and reciprocity. So speaking is a social exercise that takes place and is built between several people. These ideas come from the principle of first place in relation to the interactionist approach where KerbratOrecchioni declares that: "All discourse is a collective construction". So Kerbrat limits the interaction, simply talking about verbal interaction. To the extent that all actions are subject to rules, joint actions therefore fall under interaction. The first remark leads us to distinguish that all human behavior comes from interaction and that all behavior gives meaning. 
Noukio Germaine Bienvenue., Sch Int J Linguist Lit, Feb, 2021; 4(2): 59-64

The Palo Alto School is, of course, inspired by its basic premise that you can't not communicate. According to Robert Vion, a gesture, an absence or a garment carry meaning.

\section{The Sequence}

This unit is the second rank of the verbal interaction made up of three elements (three exchanges): opening, main, closing which are well explained by Roulet in the following quote: "We postulate that any incursion can be analyzed at a first level in three constituents: a subordinate exchange function of opening the incursion, a main exchange function of transaction, and a subordinate exchange function offencing."

\section{The Exchange}

The third place is the exchange which has a primordial function in the verbal interaction, in which the two protagonists will get involved. It is defined as a dialogical unit which composes the interaction, insofar as the constituents are the interventions. From this perspective, Moeschler asserts that: "Exchange is the smallest dialogical unit that makes up interaction. The constituents of exchange are theinterventions which have illocutionary relations between them. "

\section{The Intervention}

Intervention is the great monologic unit of interaction. It can have various functions: initiative (opening of an exchange), reactive (reaction to the initiative) It is a response or a response. Instead of using the initiator / reactive duality, we prefer to use the simple response / cue dichotomy. "The" responses" in the strict sense, which provide requested information, and "cues" that comment on the utterance."

From what is said about the constituent units of verbal interaction, we can conclude that these units are structured in a hierarchical manner where they are nested within each other inspired by the idea of a hierarchy of grammatical units ( groups are made up of words made up of phonemes) developed by $\mathbf{M}$. Halliday".

In our study, this analysis and presentation of the elements of the interaction will help us to know the most used units. In the theoretical framework we have collected and chosen the theoretical bases on which our research is built, now we are moving towards the tangible which consists firstly in verifying the applications of all the theories consulted in the field, and secondly to confirm or refute the hypotheses already made.

\section{METHODOLOGY}

To carry out this study, we have opted for an appropriate methodology that facilitates the task of collecting the data necessary for our research. This method is defined by its character which is both descriptive and analytical: descriptive because in this case, it is essential to describe, first, the state of the practice of communication in its verbal aspect considered by the different approaches, analytical since it dissects the data collected in order to be of essential interest.

Our method has two components, the first concerns a questionnaire intended for learners from the LEA (Applied Foreign Languages) department, the second is reserved for the direct and non-participating observation of learners in the university environment. This observation consists of direct contact with them in order to collect recordings of verbal interactions that are as spontaneous as possible.

The importance of the questionnaire is manifested in its practicability, it has a standardized character allowing at the same time to give the same task to all the target audience without the slightest influence of our presence on their responses. The preparation of the questionnaires of our present research meets the communicative needs of the learners. These needs are summed up in the five components of Communication competence around which our distribution of questions was inspired. Since this research work has a complex corpus as a population, we have developed a questionnaire aimed at defining the subject and situating it in its personal context (gender, age, place of residence, etc.). To detect the relationship between the learner and the language in society (frequency of the learner's use of the language and its representation or image for him). These questions are related to the cognitive or psychic state of the learner. (Dyslexia, fear, shyness, stage fright...). This kind of question arose automatically because language is considered to be the platform for all verbal communication. These questions touch on grammar, vocabulary, conjugation and even spelling.

In addition to the above, the questionnaire of our research is formulated with several kinds of closed questions (aiming to delimit the answers of the questioned ones and to prevent them from being out of the thick of the matter) and some open questions to ensure the possibility of " obtain points that have not been mentioned before from us. The preparation of the questionnaire comes to identify the major difficulties that learners encounter during their verbal interactions. The questioned answer the closed questions by checking the boxes corresponding to the proposed answers (yes, no, poor, average, good ...). As for open questions, a requirement is imposed to answer freely and personally. While the so-called duplicate questions are used to check the frequency as well as the accuracy of the answers.

\section{Choice of the Corpus}

Our choice of the corpus focuses on first year students, because the latter come freshly from high 
Noukio Germaine Bienvenue., Sch Int J Linguist Lit, Feb, 2021; 4(2): 59-64

schools and colleges considered as a transit phase between school education and higher education where the learner is supposed to have a level that allows him to act in accordance with communicative requirements depending on the situation in which he finds himself. Also this year as being an entry profile at a university level implies the predisposition of this one to confront the different situations of verbal interactions. The sample consists of 100 students

\section{DATA ANALYSIS}

We will present the data collected and the results in the form of number followed by comments. On the first sociolinguistic question, it emerges that $80 \%$ of students live in cities, which is a favorable asset for practicing verbal communication in a better register in French. Unfortunately, in view of the discussions, we find that they speak without however correctly mastering what they say. The educational level of the father and mother clearly reflects the level of the learners. For example, the responses of those whose parents are academics are clear is positive. Also, we see that parents without level are the most numerous, so this factor has a negative influence on the interaction skills of their children. This provides information on the fact that the family holds the most perpendicular role.

To the third question, whether our sample communicate in classrooms, on campus and outside campus in French, it emerges that $90 \%$ of verbal communication takes place in study rooms and sometimes in the campus. Outside of these settings, it is the mother tongue or another language that takes over among our respondents. In these results, the use of code alternation sometimes represents $70 \%$ for learners. This proves the negative effect of this bad habit on the development of verbal communication strategies in a foreign language.

Here the social factor is obviously an accomplice, favoring communicative practices with a percentage of encouragement that exceeds $60 \%$. This indicates that the communicative act is minimized by negligence on the part of the learners.

When asked whether our respondents have indepth knowledge of the French language, all claim that they speak this language although they do not master all the registers and syntactic turns when the level becomes high.

The result obtained from the answers given forms increased percentages which reach $90 \%$. This percentage indicates the average wealth of cultural knowledge held by learners but this is not reflected in the field and in communicative practices. The respondents show the good representation of the French language, a percentage of $100 \%$ expresses the influx of this population towards this language.
The responses to personal reading initiatives show that in our universities, the rigor and discipline of pre-university education must be taken seriously to ensure better communication. Speaking, especially spontaneous, is one of the pillars of mastering verbal interaction. This reluctance to speak up on the part of learners is linked to their fear, stage fright, or shyness or may be the unmotivating nature of teachers.

When speaking in front of an audience that you have not mastered, there are feelings of all kinds that embed themselves in the psychic side of the learner. They cannot be neglected or their effect on the way they speak. A student who is shy can no longer interact in a flexible and understanding manner. Analysis of this question allows us to realize the difficulty of feeling embarrassed when communicating verbally in front of an audience. But the good thing here is that these learners all make an effort to achieve it.

\section{Language Questions}

When we compare the reality of the students with the practice and mastery of the language, we see that the results lack credibility on the question of whether they read and understand French correctly because, a learner who even reads from time to time can at least cope with the simple communication situation. This case can be commented as follows: These learners read but without depth or permanence.

By analyzing the question on the choice of documents to read (books, newspapers, magazines etc.) we can notice the neglect of reading on paper to move towards multimedia which is undoubtedly the essential means of the time for training and information. (Internet $60 \%$ ). $40 \%$ are interested in reading books because they discovered the importance of this precious medium by giving talks during the years at the university. Here we want to attract attention that we forgot the question "do you read a lot, little or not at all). It would beinform us if it is the constant lack of reading that was the cause of these difficulties in speaking the language.

"Do you find good words when you speak?" "The answers are very representative of the current state in which the learners find themselves and, this confirms our hypothesis on lexical poverty among students. We can say that the learner does not engage in communication situations because he does not have the linguistic means which allow him to keep face and to be comfortable in his words. This shows a thorny or even catastrophic situation due to the weakness of teaching / learning from primary school. These difficulties constitute a real blockage against spontaneous speaking, which prevents learners from behaving in a normal way when speaking orally in French.

When it comes to questions about mistakes made in writing or speaking, we see a variety of difficulties, namely: lexical, spelling and grammatical. 
Noukio Germaine Bienvenue., Sch Int J Linguist Lit, Feb, 2021; 4(2): 59-64

What is remarkable here is the stability of the percentages of errors at the respondent level. In combination, the percentage of errors is very high because of the fragility of their base from their first years of schooling because this kind of knowledge can not be obtained only by successive and permanent stages. Based on the results of the above analysis we offer the following solutions:

\section{Linguistic Solutions}

- Make learners aware of the importance of reading to enrich their lexicon;- Focus on lectures to improve pronunciation;

- Strengthen activities that are related to basic concepts (grammar, conjugation, spelling, etc.) and others that promote verbal exchanges.

- Improve curricula and study conditions according to new and recent teaching / learning theories;

- Increase the hourly volume for educational activities based on oral communication;

\section{Psychological Solutions}

Get the learner used to presenting oral presentations from his first year to consolidate his selfconfidence and put an end to his linguistic insecurity which represents a major handicap in speaking;

- Use motivation techniques and strategies (role plays in theatrical plays, etc.);

- Choice of themes of interest to the learner and in relation to his daily life;

- Do not penalize mistakes and exploit them as a means of learning and give learners a margin of freedom to express themselves.

\section{Socio-Cultural Solutions}

- Make learners aware of verbal communication practices even outside the rooms (in the social environment)

- Promote programs in French in the family environment;

\section{CONCLUSION}

During this study, we endeavored to examine the communicative practices of learners taking place in the university environment of Dschang, such a place supposed to be rich in interactions favoring the evolution of learning. Indeed, our perspective focuses mainly on highlighting the importance and role of verbal interactions, as a contemporary discipline, in the learner's intra and extra-university life. These verbal interactions allow him to improve his ability to speak with correct French in different communication situations. This is why we took communication as a starting point, interaction as a bridge and communication competence as a platform for analyzing the corpus of our investigation. These steps have brought us more or less fruitful results on which we rely to take a position on the assumptions already made at the start. Finally, any reflection on this problem situation invites the enhancement of the cooperation of all the efforts of everyone, whether teachers, learners, parents or even the whole of society.

\section{REFERENCES}

1. Dubois, J. (1996). Dictionary of French language, Larousse, Paris.

2. Moirand, S. (1982). Teaching to communicate in a foreign language, Hachette, Paris.

3. Jakobson, R. (1963). Essais de linguistics générale, Minuit, Paris.

4. Vion, R. (1992). Verbal communication: analysis of interactions, Hachette, Paris.

5. Hymes, H. D. (1984). Towards communication skills, Credif-Hatier, Paris.

6. Noam, C. (1965). Aspects of the theory of syntax, Seuil, Cambridge.

7. Salins-Géneviève, D. 1988). An ethnographic approach to communication. Encounters in a Parisian environment, Hatier-Didier, Paris.

8. Kerbrat-Orecchioni C. (1990). Les interactions verbales, Tome 1, Armand Colin, Paris.

9. Kerbrat-Orecchioni, C. (1992). Les interactions verbales, Tome 2, Armand Colin, Paris.

10. Kerbrat-Orecchioni C. (1994). Les interactions verbales, Tome 3, Armand Colin, Paris.

11. Geertz, C. (1986). Local knowledge, global knowledge. The places of knowledge, PUF, Paris.

12. Jean-Pierre, C., \& Gruca, I. (2002). Course in teaching French as a foreign and second language, Presses Universitaires, Grenoble. 